Frank J. Rizzo

Professor Emeritus

Aerospace Engineering and Engineering Mechanics

Iowa State University

\title{
List of Technical Publications, Conference Presentations, and Lectures
}

March 27, 2003

\section{Technical Publications:}

Papers in Refereed Journals, Refereed Proceedings, and Book Chapters

"An Integral Equation Approach to Boundary Value Problems of Classical Elastostatics", Quarterly of Applied Math., V. 25, No. 1, April 1967. (Landmark Paper, ASME Warner Medal 1993)

"A Direct Formulation and Numerical Solution of the General Transient Elastodynamic Problem I", J. of Math. Analysis \& Applications, V. 22, No. 1, April 1968 (with T. A. Cruse).

"A Formulation and Solution Procedure for the General Nonhomogeneous Elastic Inclusion Problem", Int. J. of Solids \& Structures, V. 4, 1968 (with D. J. Shippy).

"Elastic Inhomogeneity and Inclusion Problems", Recent Advances in Engineering Science, V. 4, Ed. A. C. Eringen, Publ. Gordon \& Breach, 1968 (with M. Stippes).

"A Method for Stress Determination in Plane Anisotropic Elastic Bodies", $\underline{\text { J. of }}$ Composite Materials, V. 4, Jan. 1970 (with D. J. Shippy).

"A Method of Solution for Certain Problems of Transient Heat Conduction", AIAA J., V. 8, No. 11, Nov. 1970 (with D. J. Shippy).

"An Application of the Correspondence Principle of Linear Viscoelasticity Theory", SIAM Journal on Numerical Analysis, V. 21, No. 2, Sept. 1971 (with D. J. Shippy).

"On The Concept of Force", Rendiconti Del Istituto Lombardo, Rend, Ser. A 107, 1973 (communicated by C. Truesdell).

"An Integral Equation Formulation of Three-Dimensional Anisotropic 
Elastostatic Boundary Value Problems", Journal of Elasticity, V. 3, No. 3, Sept. 1973 (with S. M. Vogel).

"Optic Nerve Axoplasm and Papilledema", Survey of Ophthalmology, 1975, Vol. 20, No. 3 (with J. Wirtschafter, and B. Smiley).

"The Boundary Integral Equation Method - A Modern Computational Procedure in Applied Mechanics, ASME, AMD, Vol. 11, 1975 (text of keynote lecture).

"A Note on the Body Force Integral of Classical Elastostatics", ZAMP, Vol. 28, 1977 (with M. Stippes).

"The Boundary Integral Equation Method Applied to Two Electromagnetic Field Problems", Int. J. of Electromechanics, Vol. 1, 1977 (with Y. Wu, J. A. Wagner, and D. J. Shippy).

"An Advanced Boundary Integral Equation Method for Three-Dimensional Thermoelasticity", Int. J. for Numerical Methods in Engineering, Vol. 11, 1977 (with D. J. Shippy).

"Intraocular Axonal Swelling Produced by Partial, Immediately Retrobulbar Ligature of Optic Nerve", Investigative Ophthalmology, Vol. 16, No. 6, 1977 (with J. Wirtschafter, D. Slagel, and W. J. Foxx).

"An Algorithm for the Numerical Solution of Boundary Value Problems Governed by Second Order Elliptic Systems", J. Inst. of Math. and Appl., Vol. 22, 1978 (with D. L. Clements).

"Boundary Integral Equation Analysis of Temperature and Stress in Film-Cooled Turbine Blades", Proc. of the 15th Annual Meeting of the Society of Engineering Science, December 1978 (with D. J. Shippy).

"On the Numerical Solution of Two-Dimensional Potential Problems by an Improved Boundary Integral Equation Method", J. of Computational Physics, Vol. 31, No. 1, 1979 (with G. Fairweather, D. J. Shippy, and Y. Wu).

"Recent Advances of the Boundary Element Method in Thermoelasticity", Developments in Boundary Elements - I, eds. P. K. Banerjee and R. Butterfield, Applied Scientific Publishers, London, Nov. 1979 (with D. J. Shippy).

"A Boundary Integral Approach to Potential and Elasticity Problems for Axisymmetric Bodies with Arbitrary Boundary Conditions", Mechanics Research Communications, Vol. 6, No. 2, 1979 (with D. J. Shippy).

"Computation of Double Integrals in the Boundary Integral Equation Method", Proc. 3rd Int. IMACS Conf., Lehigh, Pa., June 1979 (with G. Fairweather and D. J. Shippy). 
"Boundary Integral Solution of Potential Problems Involving Axisymmetric Bodies and Nonsymmetric Boundary Conditions", Proc. 10th SECTAM Conference, Knoxville, Tenn., April 1980 (with D. J. Shippy and A. K. Gupta).

"A Boundary Integral Equation Method for Torsion of Variable Diameter Circular Shafts and for Certain Related Problems", Proc. 2nd Int'l. Symp. on Innovative Numerical Analysis in Eng. Science, Montreal, June 1980 (with A. K. Gupta and Y. Wu).

"A BIE Method for Axisymmetric Elastostatic Bodies under Arbitrary Surface Loads", Proc. 2nd Int'l. Symp. on Innovative Numerical Analysis in Eng. Science, Montreal, June 1980 (with D. J. Shippy and R. Nigam).

"The Boundary Integral Equation Method with Application to Certain Stress Concentration Problems in Elasticity", J. Australian Math. Society, Series B, Vol. 22, 1981 (with D. J. Shippy).

"On the Effectiveness of Three Boundary Integral Equation Formulations for Certain Axisymmetric Elastostatic Problems", Res Mechanica, Vol. 4, 1982 (with D. J. Shippy).

"Boundary Integral Equation Method Calculations of Surface Regression Effects in Flame Spreading", ASME J. Heat Transfer, Vol. 104, November 1982 (with R. A. Altenkirch, M. Rezayat, and R. Eichhorn).

"Some Observations on Kelvin's Solution in Classical Elastostatics as a Double Tensor Field with Implications for Somigliana's Integral", J. of Elasticity, Vol. 13, p. 91, 1983 (with D. J. Shippy).

"Application of BIE Method to Sound Radiation Problems Using an Isoparametric Element", ASME J. Vibration and Acoustics, Vol. 106, p. 414, 1983 (with A. F. Seybert, B. Soenarko and D. J. Shippy).

"A Unified Boundary Integral Equation Method for a Class of Second Order Elliptic Boundary Value Problems", J. Australian Math. Society, Series B, Vol. 25, p. 501, 1984 (with M. Rezayat and D. J. Shippy).

"A Modern BIE Method for Elastic Wave Radiation and Scattering by Three-Dimensional Objects", ASME Publ. AMD, Vol. 60, p. 97, 1984 (with D. J. Shippy and M. Rezayat).

"A Boundary Integral Equation Method for Radiation and Scattering of Elastic Waves in Three Dimensions", Int. J. for Numerical Methods in Engineering, Vol. 21, p. 115, 1985 (with D. J. Shippy and M. Rezayat).

"An Advanced Computational Method for Radiation and Scattering of Acoustic Waves in Three Dimensions", J. Acoustical Society of America, Vol. 77, p. 362, 1985 (with A. F. Seybert, B. Soenarko and D. J. Shippy). 
"A BIE Method for Time-Harmonic Radiation and Scattering in an Elastic HalfSpace," ASME Publ. AMD, Vol. 72, p. 83, 1985 (with M. Rezayat and D. J. Shippy).

"A Boundary Element Method for Axisymmetric Bodies", Developments in Boundary Element Methods-4, Chap. 3, Applied Science Publishers, London, 1986 (with D. J. Shippy).

"On Time-Harmonic Elastic Wave Analysis by the Boundary Element Method for Moderate to High Frequencies", Computer Methods in Applied Mechanics and Engineering, Vol. 55, p. 349, 1986 (with M. Rezayat and D. J. Shippy).

"A Special Integral Equation Formulation for Acoustic Radiation and Scattering for Axisymmetric Bodies and Boundary Conditions", J. Acoustical Society of America, Vol. 80, No. 4, p. 1241, 1986 (with A. F. Seybert, B. Soenarko, and D. J. Shippy).

"On the Computation of Two-Dimensional Stress Intensity Factors Using the Boundary Element Method," International Journal for Numerical Methods in Engineering, Vol. 26, p. 2739, 1988 (with Z. H. Jia and D. J. Shippy).

"The Boundary Element Method - Some Early History - A Personal View", Chapter One of Boundary Element Methods in Structural Analysis, D. E. Beskos, ed., ASCE publ., 1989. Japanese translation by M. Kitahara appears in the Journal of Mathematical Analysis, Vol. 2, No. 296, January 1988.

"On Boundary Integral Equations for Crack Problems," Proceedings of the Royal Society of London, A, Vol. 421, p. 341, 1989 (with P. A. Martin).

"On Hypersingular Boundary Integral Equations for Certain Problems in Mechanics," Mechanics Research Communications, Vol. 16, No. 2, p. 65, 1989 (with P. A. Martin and I. R. Gonsalves).

"Three-Dimensional Crack Analysis Using the Boundary Element Method," Int. J. for Numerical Methods in Engineering, Vol. 28, p. 2257, 1989 (with Z. H. Jia and D. J. Shippy).

"Direct Boundary Integral Equations for Elastodynamics in Three-Dimensional Half-Spaces," Computational Mechanics, Vol. 6, p. 279, 1990 (with I. R. Gonsalves and D. J. Shippy).

"Hypersingular Boundary Integral Equations: Some Applications in Acoustic and Elastic Wave Scattering," ASME Journal of Applied Mechanics, Vol. 57, p. 404, 1990 (with G. Krishnasamy, L. W. Schmerr, and T. J. Rudolphi).

"Boundary Element Analysis of Wave Scattering from Cracks," Communications in Applied Numerical Methods, Vol. 6, p. 591, 1990 (with Z. 
H. Jia and D. J. Shippy).

"A Boundary Element Model for Acoustic-Elastic Interaction with Applications in Ultrasonic NDE," Journal of Nondestructive Evaluation, Vol. 9, No. 2/3, pp. 101-112, 1990 (with P. P. Goswami, T. J. Rudolphi, and D. J. Shippy).

"Application of the Boundary Element Method to Elastic Wave Scattering by Irregular Defects," Journal of Nondestructive Evaluation, Vol. 9, No. 2/3, pp. 113-127, 1990 (with P. J. Schafbuch and R. B. Thompson).

"The Direct Boundary Integral Equation Method for the Three-Dimensional Elastodynamic Transmission Problem," Mathematical and Computer Modelling, Vol. 15, p. 155, 1991 (with I. R. Gonsalves and D. J. Shippy).

"Continuity Requirements for Density Functions in the Boundary Integral Equation Method," Computational Mechanics, Vol. 9, p. 267, 1992 (with G. Krishnasamy).

"A Weakly-Singular Form of the "Hypersingular" Boundary Integral Equation Applied to 3-D Acoustic Wave Problems," Computer Methods in Applied Mechanics and Engineering, Vol. 96, p. 271, 1992 (with Y.J. Liu).

"Hypersingular Boundary Integral Equations: Their Occurrence, Interpretation, Regularization and Computation," Developments in BEM 7-Advanced Dynamic Analysis, eds. P. K. Banerjee and S. Kobayashi, Elsevier Science Publishers Ltd., 1992 (with G. Krishnasamy and T. J. Rudolphi).

"Eigenfrequencies of an Elastic Sphere with Fixed Boundary Conditions," ASME J. of Applied Mechanics, Vol. 59, p. 458, June 1992, (with P. J. Schafbuch and R. B. Thompson).

"A General Algorithm for the Numerical Solution of Hypersingular Boundary Integral Equations," ASME J. of Applied Mechanics, Vol. 59, p. 604, September 1992, (with M. Guiggiani, G. Krishnasamy, and T. J. Rudolphi).

"Elastic Scatterer Interaction via Generalized Born Series and Farfield Approximations," Journal of the Acoustical Society of America Vol. 93(1), P. 295-307, January 1993, (with P. J. Schafbuch and R. B. Thompson).

"Hypersingular Boundary Integral Equations for Radiation and Scattering of Elastic Waves in Three Dimensions," Computer Methods in Applied Mechanics and Engineering Vol. 107, p. 131-144, 1993, (with Y.J. Liu).

"Boundary Element Method Solutions for Elastic Wave Scattering in 3D," Int. J. for Numerical Methods in Engr. Vol. 36, p. 432-455, 1993 (with P. J. Schafbuch and R. B. Thompson).

"Boundary Integral Equations for Thin Bodies," Int. J. for Numerical Methods 
in Engineering, Vol. 37, No. 1, p. 107-121, 1994, (with G. Krishnasamy and Y.J. Liu).

"Regularized Integral Equations and Curvilinear Boundary Elements for Electromagnetic Wave Scattering in Three Dimensions," IEEE Trans. on Antennas and Propagation Vol. 43, No. 12, pp.1416-1422, 1995, (with J.C. Chao, Y.J. Liu, P.A. Martin and L. Udpa).

"Partitioning and Boundary Integral Equations", Int. J. for Numerical Methods in Engr. Vol. 38, pp. 3483-3495, 1995, (with P.A. Martin).

"A General Formulation for Light Scattering by Dielectric Bodies Near a Perfectly Conducting Surface", J. Optical Soc. of Amer. Ser. A Vol. 13, No. 2, pp. 338-344, 1996, (with J.C. Chao, Y.J. Liu, P.A. Martin and L. Udpa).

"Hypersingular Integrals: How Smooth must the Density Be?", Int. J. for Numerical Methods in Engr. Vol. 39, pp. 687-704, 1996, (with P.A. Martin).

"Scattering of Elastic Waves from Thin Shapes in 3-D using the Composite Boundary Integral Equation Formulation", J. Acoustical Society of America, Vol. 102, No. 2, pp. 926-932, 1997, (with Y.J. Liu).

"Some Efficient Boundary Integral Strategies for Time-Harmonic Wave Problems in an Elastic Halfspace", Computer Methods in Applied Mechanics and Engineering, 164, pp. 207-221, 1998 (with L. Pan and P.A. Martin).

"Boundary Element Analysis for Composite Materials and a Library of Green's Functions", Computers and Structures, Vol. 66, No. 5, pp. 685-693, 1998 (with L. Pan and D. O. Adams).

"Smoothness-Relaxation Strategies for Singular and Hypersingular Integral Equations", Int. J. for Numerical Methods in Engr. 42, pp. 885-906, 1998 (with P. A. Martin and T. A. Cruse).

"Stress Intensity Sensitivities via Hypersingular Boundary Integral Equations", Computational Mechanics, Vol. 23, pp. 389-396, 1999 (with D. Zhang and T. J. Rudolphi).

"A Boundary Element Strategy for Elastostatic Inverse Problems Involving Uncertain Boundary Conditions", Int. J. for Numerical Methods in Engr., Vol. 46, pp. 957-972, 1999 (with S. Lu).

\section{Papers in Non-refereed Proceedings (last 15 years)}

"Acoustic Scattering by Elastic Solids Using the Boundary Element Method", Review of Progress in Quantitative NDE, Williamsburg, VA, June 1987 (with P. Goswami and D. J. Shippy). 
"The Finite and Boundary Element Methods: One View of Their Foundations," Proc. Fourth JASCOME Symposium on Boundary Element Methods, Tokyo, Japan, December 1987 (text of keynote lecture).

"Boundary Element Methods for Acoustic and Elastic Wave Scattering," Proc. Fourth JASCOME Symposium on Boundary Element Methods, Tokyo, Japan, December 1987 (with P. Goswami and D. J. Shippy).

"The Finite and Boundary Element Methods: One View of Their Foundations", Proc. IUTAM Symposium, Advanced Boundary Element Methods, San Antonio, Texas, 1987 (text of keynote lecture), Springer-Verlag Publ., 1988.

"On the Use of Strongly Singular Integral Equations for Crack Problems," Proc. Tenth International Conference on Boundary Element Methods, Southampton, England, September 1988 (with T. J. Rudolphi, G. Krishnasamy, and L. W. Schmerr).

"Boundary Integral Equation Formulations for Scattering of Elastic Waves in Three-Dimensional Half-Spaces," Proc. Int'l. Conf. on Computational Eng. Science (ICES), Atlanta, GA, April 1988 (with I. R. Gonsalves and D. J. Shippy).

"Elastic Wave Scattering by Arbitrarily Shaped Voids," Review of Progress in Quantitative NDE, La Jolla, CA, August 1988 (with P. Schafbuch, R. B. Thompson, and T. J. Rudolphi).

"Hypersingular Integral Equations for Crack Problems," Review of Progress in Quantitative NDE, La Jolla, CA, August 1988 (with G. Krishnasamy, L. W. Schmerr, and T. J. Rudolphi).

"Hypersingular Integral Formulas and Wave Scattering with the Boundary Element Method," Proc. First Joint Japan-U.S. Symposium on Boundary Element Methods, Tokyo, Japan, October 1988 (with G. Krishnasamy, T. J. Rudolphi, and L. W. Schmerr).

"Discretization Considerations with Hypersingular Integral Formulas for Crack Problems," Proc. IUTAM/IACM Symposium on Discretization Methods in Structural Mechanics, Vienna, Austria, June 1989 (with G. Krishnasamy, T. J. Rudolphi, and L. W. Schmerr).

"Elastic Wave Scattering by Irregular Shaped Flaws," Review of Progress in Quantitative NDE, Brunswick, Maine, August 1989 (with P. Schafbuch, R. B. Thompson, and T. J. Rudolphi).

"Acoustic Scattering by Submerged Elastic Bodies: A Boundary Element Approach," Review of Progress in Quantitative NDE, Brunswick, Maine, August 1989 (with P. Goswami and T. J. Rudolphi). 
"Scattering of Acoustic and Elastic Waves from Cracks Using Hypersingular Boundary Integral Equations," Proc. IUTAM Symposium on Elastic Wave Propagation and NDE, Boulder, Colorado, July 1989 (with T. J. Rudolphi and G. Krishnasamy).

"Static and Time-Harmonic Boundary-Element Analysis of Cracks in ThreeDimensional Elastic Bodies," Proc. Midwest Mechanics Conference, Houghton, Michigan, August 1989 (with D. J. Shippy and Z. H. Jia).

"Some Observations on the Boundary Element Method," Proc. International Symposium on Boundary Element Methods, East Hartford, Connecticut, October 1989 (text of invited lecture).

"Overcoming Nonuniqueness in the Direct BIEM for Three-Dimensional Steady-State Exterior Elastodynamic Problems," Proc. International Symposium on Boundary Element Methods, East Hartford, Connecticut, October 1989 (with I. R. Gonsalves and D. J. Shippy).

"Ultrasonic Transmission Through a Curved Interface," Review of Progress in Quantitative NDE, La Jolla, California, July 1990 (with P. P. Goswami, T. J. Rudolphi, and R. R. Roberts).

"Time-Harmonic Elastic-Wave Scattering: The Role of Hypersingular Boundary Integral Equations," Proc. International Association for Boundary Element Methods, Rome, Italy, October 1990 (with G. Krishnasamy).

"Hypersingular Boundary Integral Equations: A New Approach to Their Numerical Treatment," Proc. International Association for Boundary Element Methods, Rome, Italy, October 1990 (with M. Guiggiani, G. Krishnasamy, and T. J. Rudolphi).

"Scattering of Acoustic and Elastic Waves by Cracklike Objects: The Role of Hypersingular Integrals," Review of Progress in Quantitative NDE, Brunswick, Main, July 1991 (with G. Krishnasamy and Y. J. Liu).

"Continuity Requirements for Density Functions in the Boundary Integral Equation Method," Proc. International Conference on Computational Engineering Science, Melbourne, Australia, August 1991 (with G. Krishnasamy and T. J. Rudolphi).

"Application of Overhauser $\mathrm{C}^{1}$ Continuous Boundary Elements to "Hypersingular" BIE for 3-D Acoustic Wave Problems," Proc. Thirteenth International Conference on Boundary Element Methods, Tulsa, Oklahoma, August 1991 (with Y. J. Liu).

"Recent Developments in Boundary Element Methods for Elastic Wave Scattering from Voids," Proc. Midwest Mechanics Conference, Rolla, Missouri, October, 1991 (with P. J. Schafbuch and Y. J. Liu). 
"Some Advances in Boundary Integral Methods for Wave Scattering from Cracks," special issue of Acta Mechanica, as proceedings of an ASME Smposium in celebration of Bruno A. Boley's sixth-fifth birthday, Atlanta, Georgia, December 1991 (with G. Krishnasamy and Y. J. Liu).

"Elastic Wave Scattering by Multiple Inclusions," Proc. of an ASME Symposium on Enhancing Analysis Techniques for Composite Materials, Atlanta, Georgia, December 1991 (with P. J. Schafbuch and R. B. Thompson).

"A Weakly Singular Form of the Hypersingular Boundary Integral Equation for 3-D Elastodynamic Problems," Proc. International Association for Boundary Element Methods, Boulder, Colorado, August 1992 (with Y. J. Liu).

"A Boundary Element Method for Scattering of Waves by Thin Shapes," Proc. International Association for Boundary Element Methods, Boulder, Colorado, August 1992 (with G. Krishnasamy and Y. J. Liu).

"Eddy Current Analysis for 3-D Problems Using the Boundary Element Method," Review of Progress in Quantitative NDE, La Jolla, California, July 1992 (with Y. J. Liu and N. Nakagawa).

"Electromagnetic Scattering Modeling Using Boundary Element Method," Proc. 2nd Annual Midwest Electrotechnology Conf., Iowa State University, April 1993, (with J. Chao, Y. J. Liu, L. Udpa, and P. Martin)

"Boundary Integral Equations for Bodies of Small, but Finite, Thickness," Proc. 8th Int. Workshop on Water Waves \& Floating Bodies, St. John's, Newfoundland, May 23-26, 1993, (with P.A. Martin)

"Ultrasonic Scattering from Open Cracks in 3-D Using a Composite Boundary Integral Equations Formulation," Review of Progress in Quantitative NDE, Brunswick, Maine, August 1993, (with Y. J. Liu)

"Electromagnetic Wave Scattering: A Modern Boundary Element Approach for NDE Applications," Review of Progress in Quantitative NDE, Brunswick, Maine, August 1993, (with J. Chao, Y. J. Liu, P.A. Martin, L. Udpa)

"Nearly Singular and Hypersingular Integrals in the Boundary Element Method," Boundary Elements XV, Proc. of the 15th Int. Conf. on Boundary Elements, Worcester, Massachusetts, August 1993, (with Y. J. Liu, D. Zhang)

"A Boundary Element Method for Scattering of Electromagnetic Waves by Homogeneous Dielectric Objects in Three Dimensions," Proc. Int. Symposium on Boundary Element Methods, Braunschweig, Germany, August 1993, (with J. Chao, Y. J. Liu, P.A. Martin, L. Udpa)

"Boundary Elements and a Green's Function Library," Proc. NIST Workshop on 
Green's Functions, Boundary Elements, and Advanced Materials Modeling, Boulder, Colorado, August 1994.

"Exact Green's Functions and the Boundary Element Method" Boundary Elements XVII, Proc. of the 17th Int. Conf. on Boundary Elements, Madison, Wisconsin, July 1995, (with P. Martin, L. Pan, and D. Zhang)

"A Multi-Region Boundary Element Solution to Interface Problems in Ultrasonic Wave Scattering" Proc. of the 24th Midwestern Mechanics Conference, Ames, Iowa, October, 1995, (with S. Shenoy and T. J. Rudolphi)

"Discretized Green's Functions and an Idea for a Library" Proc. of the 24th Midwestern Mechanics Conference, Ames, Iowa, October, 1995, (with L. Pan)

"Sensitivity Boundary Integral Equations with Applications to Crack Problems" Proc. of the 24th Midwestern Mechanics Conference, Ames, Iowa, October, 1995, (with D. Zhang)

\section{Conference Presentations:}

\section{At Society Meetings}

All of the above papers which appeared in refereed proceedings, or any ASME publication, were also orally presented at an associated conference by (at least) one of the indicated authors.

\section{Other Conference Presentations on Current Research (some with coauthors, last 20 years)}

Atlanta, Georgia, May 1984; ASCE Spring Conference

Blacksburg, Virginia, Oct. 1984; 21st Meeting of Soc. Eng. Science

State College Pennsylvania (Penn. State), Oct. 1985; 22nd Meeting of Soc. Eng. Science

Buffalo, New York, May 1987; ASCE Eng. Mech. Div. Specialty Conf.

Lexington, Kentucky, May 1988; NSF-Conf. Board on Math. Sci. Specialty Conference on Math. Foundations of Boundary Element Method

Chicago, Illinois, November 1988; ASME Winter Annual Mtg.

Houghton, Michigan, August 1989; Midwest Mechanics Conference

Newark, Delaware, September 1989; ONR Workshop on Integral and Field Equation Methods in Fluid-Structure Interaction

Dallas, Texas, November 1990, ASME Winter Annual Meeting

State College Pennsylvania (Penn State), March 1991, ONR Workshop on Fluid-Structure Interaction

Washington, D.C., July 1991, Soc. Ind. and Applied Math (SIAM) Meeting

Chicago, IL, July 1991, 1st US Nat'l. Congress on Computational Mechanics

Albuquerque, NM, June 1992, Boundary Element Technology Conf. 
Tokyo Japan, August 1994, Third World Congress on Computational Mechanics,

Argonne, Illinois, August 1994, Theory Institute on Quadrature

Seattle, Washington, July 1995, Progress in Electromagnetics Research Symp. (PIERS)

Baltimore Maryland, July 1996, ASME Mechanics and Materials Conference

San Francisco California, August 1997, 4th US Nat'l. Congress on Computational Mechanics (two presentations).

\section{Lectures:}

At Universities and Industry, on some aspect of current research (last 20 years)

University of Tennessee (Knoxville) 1984

Illinois Earthmovers Conference (Peoria) 1984

Whirlpool Engineers (in Lexington) 1984

University of Kentucky [Physics Dept.] 1985

IBM [Engineering Div.] (Lexington) 1985

Cornell University (Ithaca, NY) 1985

University of Southern California (Los Angeles) 1985

Northwestern University (Evanston, IL) 1986

Southern Methodist University (Dallas, TX) 1987

Texas A \& M University (College Station) 1987

University of Houston (Texas) 1987

Shell Development Company (Houston) 1987

Iowa State University [Math Dept.] 1987

Iowa State University [M.E. Dept.] 1987

Tokai University (Japan) 1987

David Taylor Naval Ship R\&D Center [2 Lectures, Training Seminar on Boundary Elements] (Washington, DC) 1988

University of Illinois [T\&AM Dept.] 1989

Caterpillar Tractor Co, Peoria, IL, 1990

University of Notre Dame, [M.E. Department] 1990

Purdue University, Aero Department, 1990

Universita Degli Studi Di Pisa, Dept. Di Costruzioni Meccaniche E, 1990

Politechnico di Milano, Dipartimento di Ingegnria Strutturale, 1990

Worcester Polytechnic University, Worcester, MA, 1991

Arizona State University [3 lectures] (Tempe) 1992

PDA Engineering (Costa Mesa, CA) 1992

University of Iowa [Math Dept.] 1992

Iowa State University [Physics \& Astronomy Dept.] 1993

NIST (Boulder, CO) 1994

Colorado School of Mines [Engineering \& Math] 1994

University of Wisconsin [M.E. Dept.] 1996

Colorado School of Mines [Div of Engr] 1997

University of Cincinnati [M.E. Dept.] 1998 